\title{
Elektrokardiyogram Sinyalinin Uyku / Uyanıklık Evreleri için İstatistiksel Olarak İncelenmesi
}

\author{
Muhammed Kürşad UÇAR* ${ }^{* 1}$, Mehmet Recep BOZKURT ${ }^{1}$, Cahit BiLGİN ${ }^{2}$ \\ ${ }^{1}$ Sakarya Üniversitesi, Mühendislik Fakültesi, Elektrik-Elektronik Mühendisliği, 54187, Sakarya, Türkiye \\ (ORCID:*1 https://orcid.org/0000-0002-0636-8645) \\ (ORCID: ${ }^{1}$ https://orcid.org/0000-0003-0673-4454) \\ ${ }^{2}$ Sakarya Üniversitesi, Tıp Fakültesi, 54187, Sakarya, Türkiye \\ (ORCID: ${ }^{* 2}$ https://orcid.org/0000-0003-2213-5881)
}

(Alınış / Received: 18.04.2020, Kabul / Accepted: 05.07.2020, Online Yayınlanma / Published Online: 20.08.2020)

\section{Anahtar Kelimeler \\ İstatistiksel sinyal işleme \\ Uyku / Uyanıklık analizi \\ Elektrokardiyografi \\ İstatistiksel analiz \\ Korelasyon hesab1}

Özet: Uyku evreleme uyku laboratuvarlarında sıklıkla kullanılan hastalık teşhis yöntemlerinin önemli bir aşamasıdır. Bireyden alınan elektroensefalografi, elektrookulogram ve elektromiyografi gibi biyolojik sinyallerin uzman doktor tarafindan incelenmesiyle birlikte uyku evreleri tespit edilir. 5 farklı evre vardır. Bunlar Uyanıklık, Evre 1, Evre 2, Evre 3 ve Hızlı Göz Hareketleri evresidir. Bazı hastalıklarda uykunun her evresinin belirlenmesine ihtiyaç yoktur. Sadece Uyku / Uyanıklık durumlarının belirlenmesi yeterlidir. Bu çalışmada, daha kolay elde edilebilir olan elektrokardiyografi sinyali ile Uyku / Uyanıklık durumları arasındaki ilişki istatistiksel olarak incelenmiştir. Bunun için iki bireyden alınan uyku kayıtları sayısal filtreler ile temizlenmiş ve 30 saniyelik epoklara bölünmüştür. Her epoktan 25 adet özellik çıkarılmış ve özelliklerin Uyku / Uyanıklık ile arasındaki istatistiksel ilişki saptanmıştır. 25 özelliğin 21'inin Uyku / Uyanıklık ile istatistiksel olarak $(p<0.05)$ ilişkili olduğu tespit edilmiştir. Sonuç olarak elektrokardiyografi sinyalinin Uyku / Uyanıklık tespitinde kullanılabileceği kanısına varılmıştır.

\section{Statistical Analysis of Electrocardiogram Signal for Sleep / Awake Stages}

\section{Keywords}

Statistical Signal Processing Sleep / Awake Analysis Electrocardiography Statistical analysis

Correlation Calculation

\begin{abstract}
Sleep staging is an important stage of the disease diagnosis methods commonly used in sleep laboratories. pecialist physician detects sleep stages according to biological signals such as electroencephalography, electrocyogram and electromyography. There are 5 different stages. These are Awake, Stage 1, Stage 2, Stage 3 and Rapid Eye Movement Sleep. In some diseases, there is no need to determine each stage of sleep. It is sufficient to determine only the Sleep / Awake stages. In this study, the relationship between electrocardiographic signal and Sleep / Awake states which are more easily available was analyzed statistically. For this purpose, sleep records from two individuals were cleaned with numerical filters and divided into 30 second epochs. Twenty-five features were removed from each epoch and a statistical relationship was found between the features of Sleep and Awake. 21 of the 25 features were found to be correlated with Sleep / Awake $(p<0.05)$. As a result, it has been concluded that electrocardiography signal can be used in sleep / awake detection.
\end{abstract}

\section{Giriş}

Uyku evreleme, uyku ile ilişkili 80'den fazla hastalığın teşhisinde uyku laboratuvarlarında kullanılan temel ve ilk adım yöntemdir [1]. Uyku evrelemede amaç, hastanın uykuda olup olmadığını, uykuda ise hangi uyku evrelerinde bulunduğunu gece boyunca tespit edebilmektir. Bu temel aşamanın sonrasında hastanın yaşadığı farklı olaylar kayıtlara işlenir. Daha sonra doktor tarafindan kayıtlar incelenerek olayların hangi evrelerde meydana geldiği, olayların uyku evreleri ile bir ilişkisi olup olmadığı tespit edilmeye çalışılır [2]. Uyku evreleme bazı hastalıkların teşhisinde vazgeçilmez bir adımdır.

Uyku evreleri, Elektroensefalogram (EEG), Elektrookülogram (EOG) ve Elektromyogram (EMG) sinyallerine göre Uyanık, Evre 1, Evre 2, Evre 3 veya REM olarak doktor tarafından etiketlenebilir. Ancak bazı durumlarda bu kadar detaylandırmaya gerek olmayabilir. Bu durumda iş gücünden tasarruf yolu seçilmelidir. Örneğin Obstrüktif Uyku Apne teşhisinde hastanın Uyku / Uyanıklık durumlarının tespit edilmesi yeterlidir [3]. Bu durumdan sonra hastanın uykuda meydana gelen anormal solunumsal olayları belirlenir. Teşhis anormal solunumsal olayların sayısına göre 


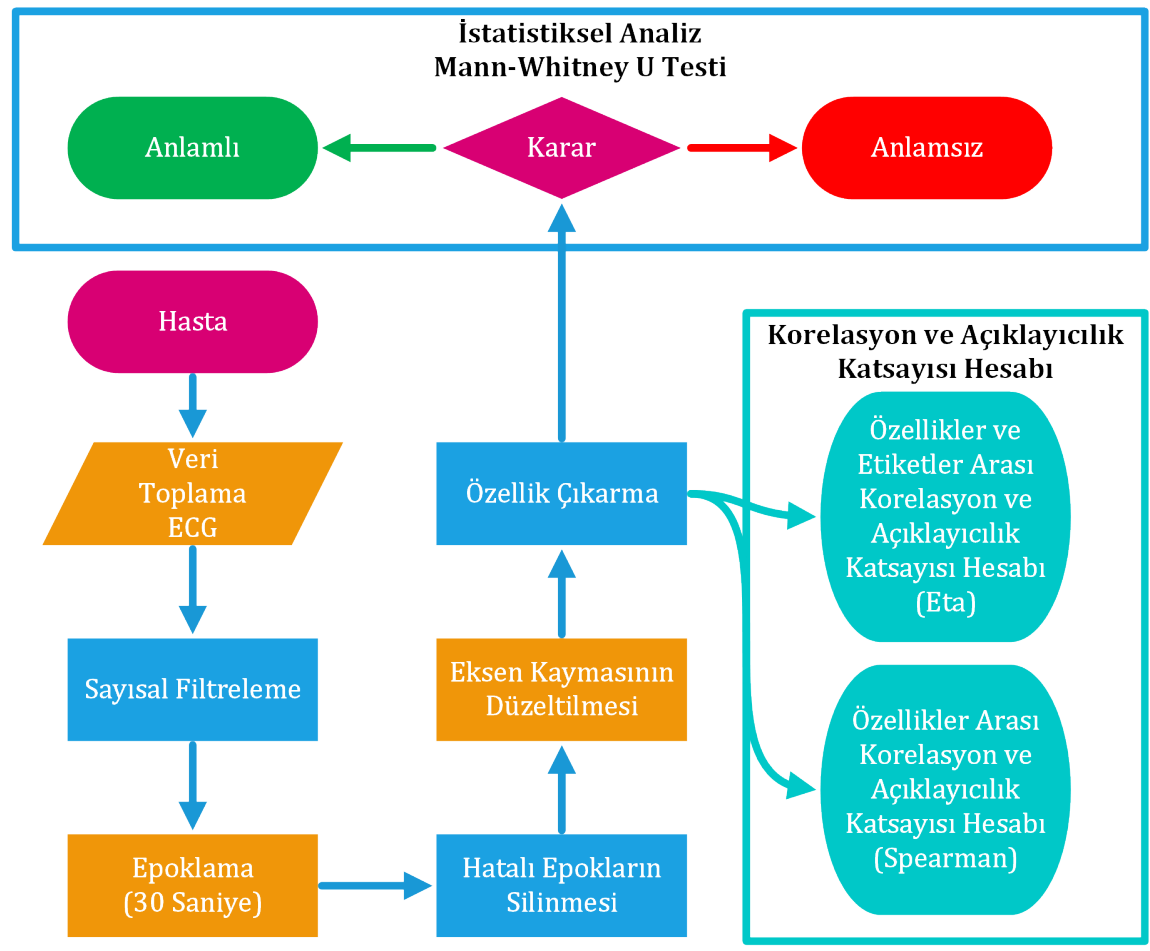

Şekil 1. Akış Diyagramı

konur. Ancak önemli nokta bu olayların uykuda meydana gelmiş olmasıdır. Bu yüzden hastanın uykuda geçen süresi ve uykuda meydana gelen anormal solunumsal olaylarının tespit edilmesi yeterlidir [4]. Literatürde uyku evreleme işlemleri EEG [5], Elektrokardiyografi (ECG) [6], Fotopletismografi (PPG) [1,7] sinyalleri ile yapilabilmektedir. Ancak bu çalışmalar genellikle sınıflandırma tabanlıdır $[1,5,6]$. Bu yüzden sinyalleri temsil eden özelliklerin gerçekten uyku evreleri ile olan ilişkisi istatistiksel olarak ispatlanmamıştır.

Bu çalışmada ECG sinyali ile Uyku / Uyanıklık arasındaki ilişkinin istatistiksel olarak incelenmesi üzerine bir uygulama gerçekleştirilmiştir. Bunun için ECG sinyalini temsil edebilecek 25 adet istatistiksel özellik çıkarılmış ve Mann-Whitney U testi ile istatistiksel $p$ değeri, korelasyon $R$ katsayısı ve $R^{2}$ açıklayıcılık katsayısı hesaplamıştır. Bunlara ek olarak yüksek korelasyona sahip özelliklerin kendi aralarındaki korelasyonları incelenmiş̧ir. Çalışma sonucunda ECG'den çıkarılan 25 istatistiksel özelliğin 21'inin Uyku / Uyanıklık analizlerinde kullanılabileceği istatistiksel olarak ispatlanmıştır.

\section{Materyal ve Yöntem}

Uygulama Şekil 1'deki adımlara göre gerçekleştirilmiştir. İlk olarak kliniğe başvuru yapan bireylerden ECG kayıtları alınmıştır. Toplanan veriler işlenebilir hale dönüştürülmüştür. Sinyal üzerinde bulunan gürültü bileşenleri temizlenmiş ve uyku evreleme işlemi için 30 saniyelik epoklara bölünmüştür. Epoklar gözle tek tek kontrol edilmiş ve artefaktlı epoklar silinmiştir. Daha sonra eksenlerde meydana gelen kaymalar giderilmiş ve her epoktan özellik çıkarılmıştır. Nihayetinde çıkarılan özellikler istatistiksel olarak incelenmiştir.

\subsection{Verilerin Toplanması ve Sinyal Ön İşleme}

Tibbi veriler Hendek Devlet Hastanesi, Uyku Laboratuvarında uzman doktor ve uyku teknisyeni gözetiminde 33 kanal SOMNOscreen Plus Polisomnografi (PSG) cihazı ile iki bireyden toplanmıştır. Bireylere ait kayıtlar ortalama 8 saatlik sinyalleri kapsar. Bu çalışmada sadece ECG sinyali kullanılmıştır ve sinyalin örnekleme frekansı $256 \mathrm{~Hz}$ 'dir. Bireylere ait demografik bilgiler Tablo 1'de özetlenmişsir. Toplanan kayitlar uzman doktor tarafindan incelenmiş ve EEG'ye göre Uyanık, Evre 1-2-3 veya REM olarak evrelenmiştir. Ancak bu çalışmada uyku / uyanıklık analizi gerçekleştirilmeye çalışıldığı için Uyanıklık / Uyku olarak etiketler birleştirilmiş̧ir.

Tablo 1. Demografik bilgiler

\begin{tabular}{lcc} 
Cinsiyet & Erkek & Kadın \\
\hline Yaş $(\mathrm{YBl})$ & 64 & 58 \\
\hline A ğırlık $(\mathrm{kg})$ & 98.1 & 117 \\
\hline Boy $(\mathrm{cm})$ & 175 & 167 \\
\hline Vücut Kitle İndeksi $\left(\mathrm{kg} / \mathrm{m}^{2}\right)$ & 32 & 42 \\
\hline Apne Hipopne İndeksi $(A H I)$ & 12.7 & 10.9
\end{tabular}

Sinyal filtreleme üç adımda gerçekleştirilmiştir. İlk olarak $0.1-100 \mathrm{~Hz}$ Chebyshev Type II filtresi ile genel gürültüler temizlenmiştir. Daha sonra şebeke gürültüsünün bastırılabilmesi için $50 \mathrm{~Hz}$ 'lik çentik filtre uygulanmıştır. Son olarak Moving Average Filtresi ile sinyal üzerindeki dalgalanmalar temizlenmiştir. Filtreleme sonrası sinyal 30 saniyelik epoklara ayrılmıştır. Epoklanan her ECG sinyali gözle kontrol edilerek artefaktlı epoklar çalışma dışı bırakılmıştır. Daha sonra eksende meydana gelen dalgalanmalar giderilmiştir. Bunun için ECG sinyali üzerine düşük dereceli bir polinom denklem uydurulur. Daha 

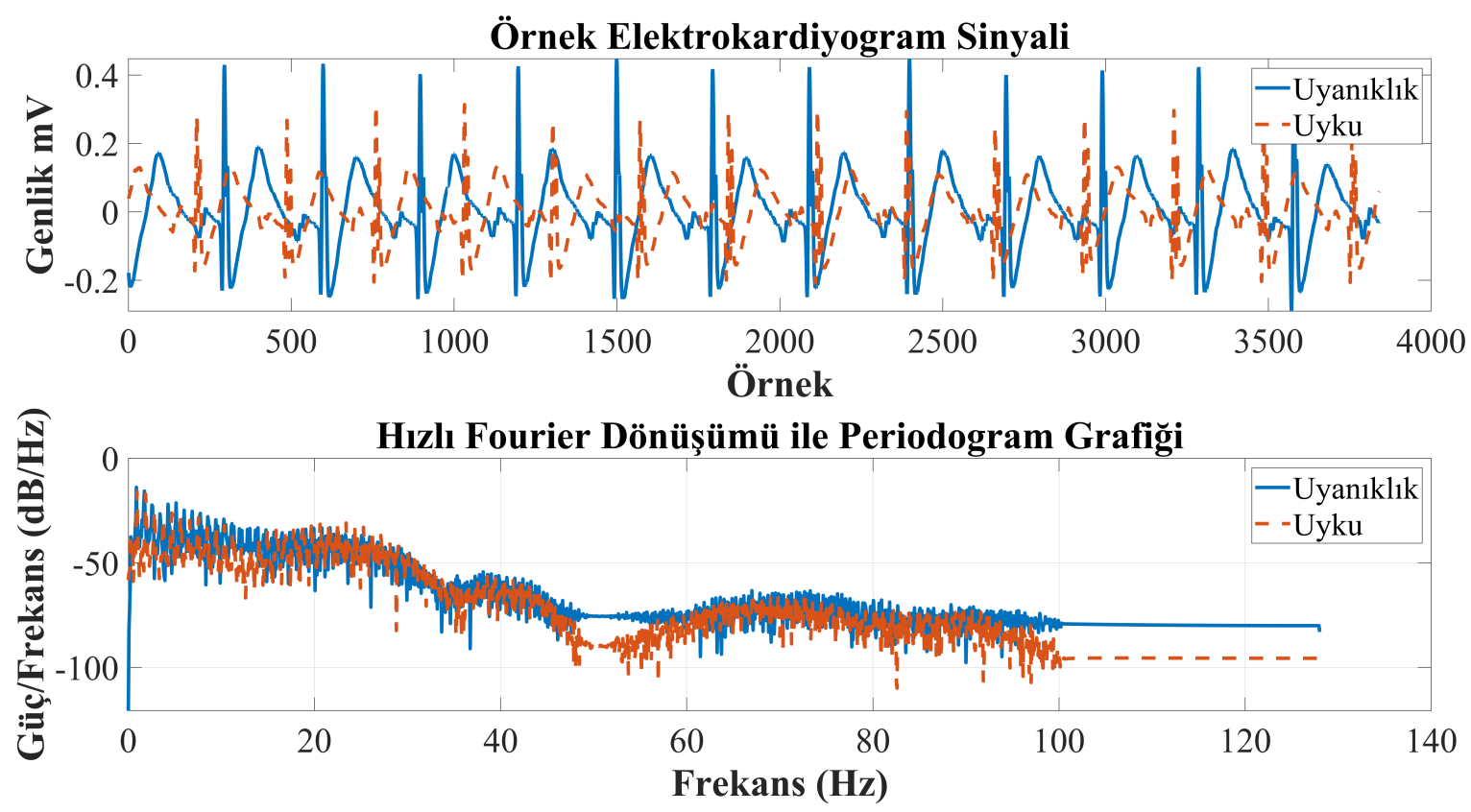

Şekil 2. Elektrokardiyogram için periodogram grafiği

sonra bilinen denklem dalgalı sinyalden çıkarılarak eksen dalgalanması temizlenmiş olur. Temizlenen ECG sinyallerinden birer epok (Uyku / Uyanıklık) Şekil 2'de Hızlı Fourier Dönüşümü alınarak periodogram grafiği ile birlikte gösterilmiştir. Epoklar temizlendikten sonra iki bireyden toplam 1511 epok elde edilmiştir. Bireylerden alınan kayıtların dağılımı Tablo 2'de özetlenmiştir.

Tablo 2. Verilerin Dağılımı

\begin{tabular}{lccc} 
Cinsiyet & Erkek & Kadın & Toplam \\
\hline Uyanıklık & 529 & 199 & 728 \\
\hline Uyku & 249 & 534 & 783 \\
\hline Toplam & 778 & 733 & 1511 \\
\hline Her epok 30 saniyelik ECG sinyali içerir.
\end{tabular}

\section{2. Özellik Çıkarma}

Her epoktan toplam 25 özellik çıkarılmıştır. Bu özelliklerin matematiksel ifadeleri Tablo 3 'te özetlenmiştir. İfadelerdeki $x$ bir epok sinyali, $i$ ise epoktaki örnek numarasını temsil eder. Örnekleme frekans1 $256 \mathrm{~Hz}$ olduğunda 30 saniyelik bir epok $N=256 \times 30=7680$ örnek içerir.

\section{3. İstatistiksel Analiz}

ECG biyolojik bir sinyal olduğu için normal dağılım göstermemektedir [4]. Bu yüzden istatistiksel analiz için MannWhitney U Testi kullanılmıştır [8]. Sonuçlara göre özellikler değerlendirilirken $p>0.05$ ise anlamsız, $p<0.05$ ise anlamlı, yani "özellik gruplar için ayırt edici" olarak değerlendirilmiştir.

\section{Sonuçlar}

Çalışmanın amacı, genel olarak uyku laboratuvarlarında kullanılan hastalık teşhisleri için ön bir adım olan uyku evreleme işlemini pratik bir şekilde gerçekleştirilebilecek sinyal özelliklerini belirlemektir. Bunun için iki hastaya ait ECG kayıtlarından çıarılan 25 adet özellik istatistiksel olarak analiz edilmiştir.

Çıkarılan özelliklerin birbiriyle ve gruplar (Uyku / Uyanıklık) arası ilişkisinin gözlenebilmesi için saçılım grafiği hazırlanmıştır (Şekil 3). Bu grafikte, Uyku / Uyanıklık ile korelasyonu en yüksek olan 18 adet özellik 2'şerli şekilde görselleştirilmiştir. Grafikler üzerinde verilen korelasyon $R$ ve çoklu açıklayıcılık katsayısı $R^{2}$ değerleri, değişkenler sürekli sayısal değişken olduğu için Spearman Korelasyon katsayısına göre hesaplanmıştır. 6 grup özellikler arası korelasyon çok kuvvetli derecede $(0.90<R<1)$ ilişkidir. 1 grup kuvvetli ilişkiye $(0.70<R<0.89)$, 1 grup orta ilişkiye $(0.40<R<0.69), 1$ grup ise zayılf ilişkiye $(0.20<R<0.39)$ sahiptir (Şekil 3). $R=0.5$ veya $R=-0.5$ olması ilişki derecelerinin aynı ancak yönlerinin farklı olduğu anlamına gelir.

ECG sinyali normal dağılım göstermediği için sonuçlar tablosunda özelliklere ait değerler ort $\pm s t d$ şeklinde ifade edilmiştir. Analiz sonucunda 25 özellikten 21 'i anlamlı $(p<0.05)$ yani, bu özelliklerin Uyku / Uyanıklık için ayırt edici olduğu tespit edilmiştir. Ayrıca özellikler ile Uyku / Uyanıklık etiketleri arasındaki korelasyon $R$ ve açıklayıcılık katsayısı $R^{2}$ hesaplanmışırı.

21 anlamlı özellikten 4 tanesi Uyku / Uyanıklık etiketleri ile zayıf ilişkiye $(0.20<R<0.39)$ ilişkiye sahiptir. 17 tanesi ise bireysel olarak önemsenmeyecek kadar düşük ilişkiye $(0.00<R<0.19)$ sahiptir. İstatistiksel analiz sonuçları Tablo 4 'te gösterilmiştir.

\section{Tartışma}

Otonom sinir sisteminin vücudu yönetmesi ile birlikte ECG sinyali otomatik olarak belirlenir. Bu durumda ECG vücudun bir nevi göstergesidir. Pek çok hastalığın teşhisi ECG sinyali üzerinden yapılabilmektedir $[9,10]$. 
Tablo 3. ECG özellikleri ve formülleri

\begin{tabular}{|c|c|c|}
\hline $\begin{array}{c}\text { Özellik } \\
\text { Numarası }\end{array}$ & Özellik & Elde Edilişi \\
\hline 1 & Basıklık & $x_{k u r}=\frac{\sum_{i=1}^{n}(x(i)-\bar{x})^{4}}{(n-1) S^{4}}$ \\
\hline 2 & Çarpıklık & $x_{\text {ske }}=\frac{\sum_{i=1}^{n}\left(x_{i}-\bar{x}\right)^{3}}{(n-1) S^{3}}$ \\
\hline 3 & Çeyrekler arası genişlik & $I Q R=\operatorname{iqr}(x)$ \\
\hline 4 & Değişim katsayısı & $\widetilde{D K}=(S / \bar{x}) 100$ \\
\hline 5 & Geometrik ortalama & $G=\sqrt[n]{x_{1}+\cdots+x_{n}}$ \\
\hline 6 & Harmonik ortalama & $H=n /\left(\frac{1}{x_{1}}+\cdots+\frac{1}{x_{n}}\right)$ \\
\hline 7 & Hjort parametresi - Aktivite & $A=S^{2}$ \\
\hline 8 & Hjort parametresi - Hareketlilik & $M=S_{1}^{2} / S^{2}$ \\
\hline 9 & Hjort parametresi - Karmaşıklık & $C=\sqrt{\left(S_{2}^{2} / S_{1}^{2}\right)^{2}-\left(S_{1}^{2} / S^{2}\right)^{2}}$ \\
\hline 10 & Maksimum & $x_{\max }=\max \left(x_{i}\right)$ \\
\hline 11 & Medyan & $\tilde{x}= \begin{cases}x_{\frac{n+1}{2}} & : x \text { tek } \\
\frac{1}{2}\left(x_{\frac{n}{2}}+x_{\frac{n}{2}+1}\right) & : x \text { çift }\end{cases}$ \\
\hline 12 & Ortalama ya da Meydan Mutlak Sapma & $M A D=\operatorname{mad}(x)$ \\
\hline 13 & Minimum & $x_{\min }=\min \left(x_{i}\right)$ \\
\hline 14 & Moment, Merkezi moment & $C M=\operatorname{moment}(x, 10)$ \\
\hline 15 & Ortalama & $\bar{x}=\frac{1}{n} \sum_{i=1}^{n}=\frac{1}{n}\left(x_{1}+\cdots+x_{n}\right)$ \\
\hline 16 & Ortalama eğri uzunluğu & $C L=\frac{1}{n} \sum_{i=2}^{n}\left|x_{i}-x_{i-1}\right|$ \\
\hline 17 & Ortalama enerji & $E=\frac{1}{n} \sum_{i=1}^{n} x_{i}^{2}$ \\
\hline 18 & Ortalama karekök değeri & $X_{r m s}=\sqrt{\frac{1}{n} \sum_{i=1}^{n}\left|x_{i}\right|^{2}}$ \\
\hline 19 & Standart hata & $S_{\bar{x}}=S / \sqrt{n}$ \\
\hline 20 & Standart sapma & $S=\sqrt{\frac{1}{n} \sum_{i=1}^{n}\left(x_{i}-\bar{x}\right)}$ \\
\hline 21 & Şekil faktörü & $S F=X_{r m s} /\left(\frac{1}{n} \sum_{i=1}^{n} \sqrt{\left|x_{i}\right|}\right)$ \\
\hline 22 & Tekil değer ayrışımı & $S V D=\operatorname{svd}(x)$ \\
\hline 23 & $\% 25$ kırpılmış ortalama & $T 25=\operatorname{trimmean}(x, 25)$ \\
\hline 24 & $\% 50$ kırpılmış ortalama & $T 50=\operatorname{trimmean}(x, 50)$ \\
\hline 25 & Ortalama Teager Enerjisi & $T E=\frac{1}{n} \sum_{i=3}^{n}\left(x_{i-1}^{2}-x_{i} x_{i-2}\right)$ \\
\hline
\end{tabular}
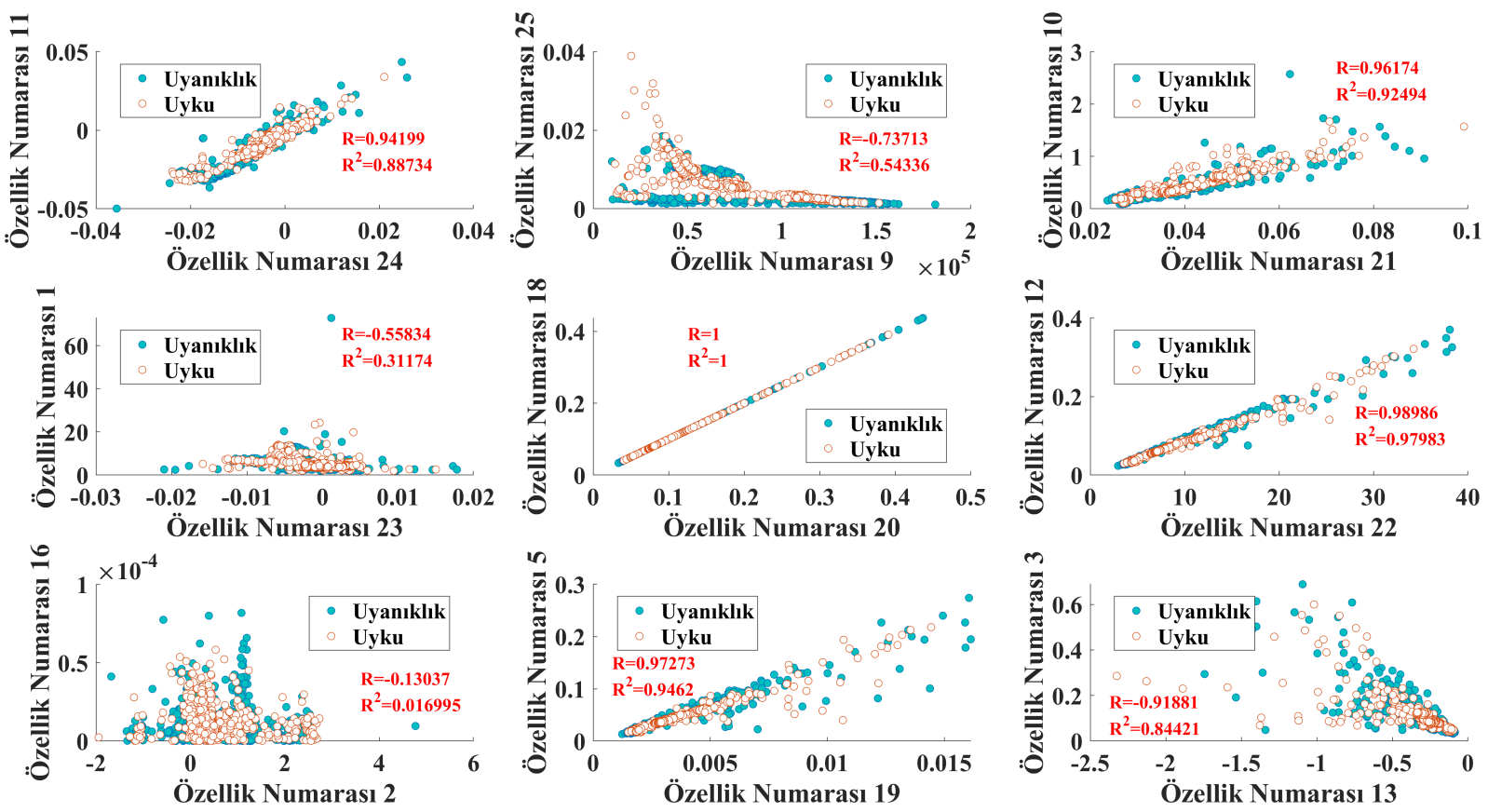

Şekil 3. Özelliklerin saçılım grafiği 
Tablo 4. İstatistiksel analiz sonuçları

\begin{tabular}{|c|c|c|c|c|c|c|c|c|c|c|c|c|c|c|c|}
\hline \multirow{4}{*}{$\begin{array}{l}\text { Özellik } \\
\text { Numarası }\end{array}$} & \multicolumn{12}{|c|}{ Grup } & \multirow{4}{*}{$R$} & \multirow{4}{*}{$R^{2}$} & \multirow{4}{*}{$p$} \\
\hline & \multirow[b]{3}{*}{ Min } & \multicolumn{3}{|c|}{ Uyanıklık } & & & \multicolumn{6}{|c|}{ Uyku } & & & \\
\hline & & & & & \multicolumn{2}{|c|}{$95 \% \mathrm{CI}$} & \multirow[b]{2}{*}{ Min } & \multirow[b]{2}{*}{ Maks } & \multirow[b]{2}{*}{ Ort } & \multirow[b]{2}{*}{ Std } & \multicolumn{2}{|c|}{ 95\% CI } & & & \\
\hline & & laks & Ort & Std & LB & UB & & & & & LB & UB & & & \\
\hline 24 & -0.0238 & 0.0211 & -0.0044 & 0.0058 & -0.0049 & -0.0040 & -0.0356 & 0.0259 & -0.0042 & 0.0072 & -0.0047 & -0.0037 & 0.318 & 0.101 & 0.000 \\
\hline 11 & -0.0324 & 0.0340 & -0.0078 & 0.0087 & -0.0085 & -0.0071 & -0.0499 & 0.0434 & -0.0075 & 0.0120 & -0.0082 & -0.0067 & 0.293 & 0.086 & 0.000 \\
\hline 9 & 11567.3 & 151377.0 & 74157.1 & 29456.6 & 71818.7 & 76495.5 & 9976.6 & 181189.5 & 85315.5 & 42531.9 & 82531.5 & 88099.5 & 0.281 & 0.079 & 0.000 \\
\hline 25 & 0.0014 & 0.0389 & 0.0066 & 0.0043 & 0.0062 & 0.0069 & 0.0010 & 0.0184 & 0.0058 & 0.0050 & 0.0055 & 0.0061 & 0.210 & 0.044 & 0.000 \\
\hline 21 & 0.0253 & 0.0992 & 0.0393 & 0.0096 & 0.0386 & 0.0401 & 0.0236 & 0.0907 & 0.0381 & 0.0111 & 0.0373 & 0.0388 & 0.194 & 0.038 & 0.000 \\
\hline 10 & 0.1100 & 1.6678 & 0.4250 & 0.2206 & 0.4074 & 0.4425 & 0.0889 & 2.5717 & 0.4085 & 0.2441 & 0.3926 & 0.4245 & 0.179 & 0.032 & 0.000 \\
\hline 23 & -0.0159 & 0.0150 & -0.0013 & 0.0036 & -0.0016 & -0.0010 & -0.0210 & 0.0178 & -0.0020 & 0.0038 & -0.0022 & -0.0017 & 0.158 & 0.025 & 0.000 \\
\hline 1 & 1.9470 & 24.2083 & 5.6016 & 2.9631 & 5.3664 & 5.8368 & 1.8802 & 72.7676 & 6.6634 & 3.6681 & 6.4233 & 6.9035 & 0.138 & 0.019 & 0.000 \\
\hline 20 & 0.0407 & 0.3908 & 0.0971 & 0.0529 & 0.0929 & 0.1013 & 0.0336 & 0.4367 & 0.0944 & 0.0593 & 0.0905 & 0.0983 & 0.116 & 0.013 & 0.000 \\
\hline 18 & 0.0407 & 0.3908 & 0.0971 & 0.0529 & 0.0929 & 0.1013 & 0.0336 & 0.4373 & 0.0944 & 0.0593 & 0.0905 & 0.0983 & 0.116 & 0.013 & 0.000 \\
\hline 22 & 3.5681 & 34.2497 & 8.5053 & 4.6376 & 8.1371 & 8.8734 & 2.9447 & 38.3197 & 8.2719 & 5.1971 & 7.9317 & 8.6121 & 0.116 & 0.013 & 0.000 \\
\hline 12 & 0.0295 & 0.3214 & 0.0714 & 0.0411 & 0.0681 & 0.0746 & 0.0234 & 0.3701 & 0.0687 & 0.0460 & 0.0657 & 0.0717 & 0.110 & 0.012 & 0.000 \\
\hline 2 & -1.9462 & 2.7319 & 0.5458 & 0.7774 & 0.4841 & 0.6075 & -1.6786 & 4.7673 & 0.8334 & 0.8421 & 0.7783 & 0.8885 & 0.108 & 0.012 & 0.002 \\
\hline 16 & 0.0000 & 0.0001 & 0.0000 & 0.0000 & 0.0000 & 0.0000 & 0.0000 & 0.0001 & 0.0000 & 0.0000 & 0.0000 & 0.0000 & 0.108 & 0.012 & 0.000 \\
\hline 19 & 0.0015 & 0.0144 & 0.0035 & 0.0019 & 0.0034 & 0.0037 & 0.0012 & 0.0161 & 0.0034 & 0.0022 & 0.0033 & 0.0036 & 0.106 & 0.011 & 0.000 \\
\hline 5 & 0.0170 & 0.2179 & 0.0438 & 0.0274 & 0.0417 & 0.0460 & 0.0133 & 0.2740 & 0.0427 & 0.0308 & 0.0407 & 0.0447 & 0.100 & 0.010 & 0.000 \\
\hline 13 & -2.3250 & -0.0940 & -0.3005 & 0.2392 & -0.3195 & -0.2815 & -1.9690 & -0.0861 & -0.2764 & 0.2107 & -0.2902 & -0.2626 & 0.082 & 0.007 & 0.000 \\
\hline 3 & 0.0406 & 0.5995 & 0.1032 & 0.0690 & 0.0977 & 0.1087 & 0.0323 & 0.6884 & 0.0996 & 0.0753 & 0.0947 & 0.1046 & 0.058 & 0.003 & 0.000 \\
\hline 6 & -30.1556 & 6.9068 & -0.0413 & 1.3155 & -0.1457 & 0.0631 & -16.0687 & 25.5265 & 0.0111 & 1.3455 & -0.0770 & 0.0991 & 0.052 & 0.003 & 0.542 \\
\hline 4 & $-6.3 \mathrm{E}+06$ & $5.0 \mathrm{E}+06$ & -3.1 .04 & $4.4 \mathrm{E}+05$ & $-6.6 \mathrm{E}+04$ & $4.0 \mathrm{E}+03$ & $-2.4 \mathrm{E}+07$ & $8.5 \mathrm{E}+06$ & $-2.5 \mathrm{E}+04$ & $1.0 \mathrm{E}+06$ & $-9.3 \mathrm{E}+04$ & $4.4 \mathrm{E}+04$ & 0.040 & 0.002 & 0.596 \\
\hline 7 & 0.0017 & 0.1527 & 0.0122 & 0.0181 & 0.0108 & 0.0137 & 0.0011 & 0.1907 & 0.0124 & 0.0202 & 0.0111 & 0.0137 & 0.032 & 0.001 & 0.000 \\
\hline 17 & 0.0017 & 0.1527 & 0.0122 & 0.0182 & 0.0108 & 0.0137 & 0.0011 & 0.1912 & 0.0124 & 0.0202 & 0.0111 & 0.0137 & 0.031 & 0.001 & 0.000 \\
\hline 14 & 0.0000 & 1.7963 & 0.0074 & 0.1033 & -0.0008 & 0.0156 & 0.0000 & 7.2802 & 0.0130 & 0.2504 & -0.0033 & 0.0294 & 0.021 & 0.000 & 0.000 \\
\hline 8 & 1327.9 & 6132.6 & 4429.5 & 380.3 & 4399.3 & 4459.7 & 1194.8 & $\begin{array}{l}6521.8 \\
\end{array}$ & 4436.8 & 434.9 & 4408.3 & 4465.3 & 0.011 & 0.000 & 0.923 \\
\hline 15 & -0.0170 & 0.0117 & 0.0000 & 0.0015 & -0.0001 & 0.0001 & -0.0199 & 0.0235 & 0.0000 & 0.0020 & -0.0001 & 0.0001 & 0.004 & 0.000 & 0.652 \\
\hline
\end{tabular}

ECG ölçümün pratik şekilde yapılabilir olması kullanımını yaygınlaştırmıştır.

Uyku / Uyanıklık durumlarında otonom sinir sistemi etkin bir şekilde çalışır. Durumlar arası değişimlerde ECG sinyalinden çıkarılan 25 özellikten 21 'inin değiştiği istatistiksel olarak $(p<0.05)$ ispatlanmıştır. Bu durum uyku ve uyanıklık sırasında kalbin farklı şekilde tepki verdiğinin bir göstergesidir. Çıkarılan özellikler ile Uyku / Uyanıklık durumları arasındaki korelasyon ilişkisinin düşük gibi görünmektedir. Ancak düşük korelasyona sahip özelliklerin bir araya getirilerek makine öğrenmesi yöntemleriyle teşhis sistemlerinde yüksek performans gösterdikleri rapor edilmiştir [4]. Sonuç olarak, ECG'nin farklı durumlardaki biçimleri kullanılarak pratik teşhis veya Uyku / Uyanıklık durumunun belirlenmesi için sistemler geliştirilebileceği söylenebilir.

\section{References}

[1] Muhammed Kürşad Uçar. Obstrüktif Uyku Apne Teşhisi için Makine Öğrenmesi Tabanli Yeni Bir Yöntem Gelistirilmesi. PhD thesis, Sakarya Üniversitesi, 2017.

[2] Richard B Berry, Rohit Budhiraja, Daniel J Gottlieb, David Gozal, Conrad Iber, Vishesh K Kapur, Carole L Marcus, Reena Mehra, Sairam Parthasarathy, Stuart F Quan, Susan Redline, Kingman P Strohl, Sally L Davidson Ward, and Michelle M Tangredi. Rules for scoring respiratory events in sleep: update of the 2007 AASM Manual for the Scoring of Sleep and Associated Events. Deliberations of the Sleep Apnea
Definitions Task Force of the American Academy of Sleep Medicine. Journal of clinical sleep medicine : JCSM : official publication of the American Academy of Sleep Medicine, 8(5):597-619, oct 2012.

[3] Muhammed Kürşad Uçar, Mehmet Recep Bozkurt, Cahit Bilgin, and Kemal Polat. Automatic sleep staging in obstructive sleep apnea patients using photoplethysmography, heart rate variability signal and machine learning techniques. Neural Computing and Applications, 29(8), 2018.

[4] Muhammed Kürşad Uçar, Mehmet Recep Bozkurt, Cahit Bilgin, and Kemal Polat. Automatic detection of respiratory arrests in OSA patients using PPG and machine learning techniques. Neural Computing and Applications, 28(10):2931-2945, oct 2017.

[5] Muhammed Kürşad Uçar, Kemal Polat, Mehmet Recep Bozkurt, and Cahit Bilgin. Uyku EEG ve EOG Sinyallerinin Sinıflandırılmasında Zaman ve Frekans Domeni Özelliklerinin Etkisi. In Tip Tekno 2014 - Tip Teknolojileri Ulusal Kongresi Bildirisi, pages 163-166, Kapadokya, Nevşehir, Türkye, 2014.

[6] Hemant Sharma and K.K. Sharma. An algorithm for sleep apnea detection from single-lead ECG using Hermite basis functions. Computers in Biology and Medicine, 77:116-124, 2016.

[7] Cahit Bilgin, Unal Erkorkmaz, Muhammed Kursad Ucar, Nese Akin, Ahmet Nalbant, and Ali Nihat Annakkaya. Use of a portable monitoring device (Somnocheck Micro) for the investigation and diag- 
nosis of obstructive sleep apnoea in comparison with polysomnography. Pakistan journal of medical sciences, 32(2):471-5, 2016.

[8] Reha Alpar. Uygulamalı istatistik ve geçerlilik güvenirlilik: Spor, să̆llk ve ĕgitim bilimlerinden örneklerle. Detay Yayıncılık, Ankara, 2 edition, 2016.

[9] Muhammed Kürşad Uçar, İnanç Moran, Deniz Turgay Altılar, Cahit Bilgin, and Mehmet Recep Bozkurt. Kronik Obstrüktif Akciğer Hastalığı ile Elektrokardiyogram Sinyali Arasındaki İlişkinin İstatistiksel Olarak İncelenmesi. Journal of Human Rhythm, 4(3):142-149, sep 2018.

[10] Nazif Onur Olcay. Acil Serviste Sağlık Çalışanlarının Elektrokardiyogram Bilgi Düzeyinin Değerlendirilmesi. Acil tıp uzmanlık tezi, T.C. Sağlık Bakanlığı, 2017. 